University of Nebraska - Lincoln

DigitalCommons@University of Nebraska - Lincoln

Sociology Department, Faculty Publications

Sociology, Department of

8-2005

\title{
Predictors of First Mental Health Service Utilization among Homeless and Runaway Adolescents
}

\author{
Terceira A. Berdahl \\ University of Nebraska-Lincoln \\ Dan R. Hoyt \\ University of Nebraska-Lincoln, dhoyt2@unl.edu \\ Les B. Whitbeck \\ University of Nebraska-Lincoln, Iwhitbeck2@unl.edu
}

Follow this and additional works at: https://digitalcommons.unl.edu/sociologyfacpub

Berdahl, Terceira A.; Hoyt, Dan R.; and Whitbeck, Les B., "Predictors of First Mental Health Service Utilization among Homeless and Runaway Adolescents" (2005). Sociology Department, Faculty Publications. 213.

https://digitalcommons.unl.edu/sociologyfacpub/213

This Article is brought to you for free and open access by the Sociology, Department of at DigitalCommons@University of Nebraska - Lincoln. It has been accepted for inclusion in Sociology Department, Faculty Publications by an authorized administrator of DigitalCommons@University of Nebraska - Lincoln. 
Published in Journal of Adolescent Health 37:2 (August 2005), pp. 145-154; doi: 10.1016/j.jadohealth.2004.08.030

Copyright () 2005 Society for Adolescent Medicine; published by Elsevier. Used by permission.

Submitted February 10, 2004; accepted August 24, 2004.

\title{
Predictors of First Mental Health Service Utilization among Homeless and Runaway Adolescents
}

\author{
Terceira A. Berdahl, Dan R. Hoyt, and Les B. Whitbeck \\ Department of Sociology, University of Nebraska-Lincoln, Lincoln, Nebraska
}

\begin{abstract}
Purpose: To describe and explain variations in first mental health service utilization before and after running away from home for homeless adolescents.

Methods: Survey interviews were conducted with homeless and runaway youth in several Midwestern locations. The effects of family of origin factors and street experiences on the likelihood of seeing a mental health professional for the first time before running away and after running away for the first time were examined. Bivariate and multivariate logistic regression methods are used to analyze these data. Interactions are tested across race and gender sub-groups.

Results: Caretaker education, caretaker rejection, and family transitions increase the probability that an adolescent first sees a mental health professional before running away from home. Post-run intervention is more likely for females, younger runaways, shelter users, youths with social support networks, and youths abused by their caretakers. A gender gap in first service use exists for Whites but not for minority youth. Minority youth who experienced family abuse were less likely than abused Whites to report ever seeing a mental health professional.

Conclusions: Analyses indicate homeless youth's utilization patterns are differentiated by family of origin factors, street experiences, timing of first utilization, and by race and gender interactions. Our findings suggest that youths whose first contact with mental health service use follows running away for the first time may experience higher levels of mental distress compared with other homeless runaways. The significant differences in first service use across race and gender subgroups should be further explored. The racial-ethnic gap in first mental health intervention for abused youths indicates this sub-group is not receiving services that are available to other homeless youths. Our findings suggest that homelessness does not homogenize racial/ethnic differences in first mental health service utilization.
\end{abstract}

Keywords: homeless youth, mental health, health services, race, gender, child abuse, victimization

Physical and mental health risks associated with homelessness are well documented [1-4]. Homeless and runaway youth exhibit high rates of depression, alcohol use, and conduct disorder [5, 6]. In addition, Padgett and Struening found high rates of street victimization $(56 \%)$, accidents and injuries (12\%), and mental health problems among homeless adults [7]. Homeless adolescents are vulnerable to numerous health problems, including nutrition, substance use, mental health, physical and sexual health, injuries and victimization $[5,8,9]$. Although homelessness creates special needs for mental health care, pathways to homelessness vary. Subsequent street experiences vary as well, creating a complex social world for these youth. We expect that these contextual variables play a role in the determining service use patterns among homeless and runaway youth. Specifically, we examine whether and when homeless youth first visit a mental health professional.

What happens to youth on the streets in terms of first service utilization for mental health concerns? Do these youth ever receive mental health care? If so, when do they first see a practitioner? Given the high risk behav- 
iors these youth engage in as well as environmental risk factors, first mental health service utilization is important to study. Our goal is to document variation in first service use for these high-risk adolescents. We examine whether or not youths see a mental health professional and look at first use before running away from home as well as after living on the streets. We establish baseline models of first service utilization that shed light on factors that influence whether or not youths are ever initiated into some kind of mental health service. Service use is modeled in terms of timing to analyze relationships among prerun and postrun risk factors and first mental health use patterns. Although all of these youths are high risk, this group is differentiated by early prerun mental health intervention, later postrun mental health intervention, and those who never see a mental health care professional. We argue that this pre-post distinction is important because divergent and overlapping factors shape the mental health needs and first service utilization patterns among homeless and runaway adolescents.

\section{Utilization of health care services among homeless and runaway youth}

Although much is known about mental health and physical health needs, our information regarding service use remains limited. Prior research has documented utilization and underutilization of health care services by homeless youths [10-12]. Service utilization is sporadic largely because homeless persons typically do not have insurance, and rely on hospitals or community health care resources for needed care.

Most utilization studies focus on hospital use. Because the homeless lack medical insurance, hospital use is higher in this population. Kushel et al. [13] found that $40 \%$ of homeless hospital patients were admitted to the hospital more than once in the past year. They found that in addition to physical health problems, victimization, arrests, housing status, and substance use increased the likelihood of using emergency health care services multiple times. In their analysis of homeless medical clinic users in Los Angeles, Yates et al. [3] reported high levels of depression (85\%), suicidal behavior $(29 \%)$, and other mental health disorders (18\%) as well as physical health problems as reasons for service use among homeless and runaway youth. Clinical and shelter studies offer estimates of reasons for utilization, but suffer from self-selection bias by definition. Homeless and runaway youth interviewed in clinical and shelter studies enhance our knowledge of many things, but predicting first mental health service use is difficult with this type of data. The present study is well suited to this topic because youth are interviewed in a variety of settings, allowing comparisons of service users with nonservice users, regardless of shelter status.

\section{Heterogeneity among the homeless and runaway ado- lescent population}

Several researchers call for an expansion of the conceptualization of homeless youth [12, 14, 15]. Homeless youth are not a homogeneous group in terms of street experiences, pathways to homelessness, or mental health needs. Youth are differentiated in terms of victimization, pathways to homelessness, social support, and demographic variables such as gender and race. These factors should influence whether or not youths see a mental health professional, as well as the timing of first visits. First, these factors may play a direct role in mental health interventions. Second, there may be moderating effects of these variables on first mental health service utilization.

\section{Methods}

Many factors influence pre- and postrun experiences that lead to mental health needs, access, and utilization. The current study examines differentiation by gender, race, family experiences and street experiences among homeless youth, and ultimately argues that these forces shape patterns in first mental health utilization for homeless adolescents. Although youths probably use hospitals as a last resort, they may use other sources of health care as well. This study addresses these gaps in the service use literature by examining whether or not youths have seen a mental health professional. We examine the likelihood of first use before and after running away from home for the first time.

\section{Gender}

Gendered components of adolescence and street life likely influence health care needs and utilization patterns. Service use patterns may be different for male and female adolescents. Ensign and Panke [16] argue that homeless and runaway adolescent girls have distinct health issues. Girls are more likely to be victims of sexual harassment and sexual assault compared with boys. Minority and lesbian girls are further marginalized. In another study, Ensign [17] reports gender differences in health care utilization behaviors. Male adolescents were less likely to seek care, as it conflicted with masculine self-images. Adolescent females were aware of their higher risk of health problems and vulnerability on the streets.

Barkin et al. [18] compared the health care utilization of subgroups of homeless women by age groups. They found that $26 \%$ of adolescent girls (aged 15-24 years) reported inpatient hospital stays in the past year. Also, adolescent girls reported five outpatient health visits on average per year. Adolescent females in this sample were more likely to hold some kind of public health insurance $(63 \%)$ compared with older women $(45 \%)$. Barkin's study highlights the importance of studying adolescent girls [18]. Older women (aged 25-34 years) in 
this study had poor health outcomes and were more likely to be involved in criminal activities and prostitution, which lead to increased physical and mental health vulnerability. Piliavin et al. [19] found that homeless adult women were about three times more likely to receive health care services compared with homeless men. Gender interactions with race/ethnicity were not tested. Cauce's study of homeless youth in Seattle found gender differences in mental health outcomes [4]. She found that girls were more likely to experience posttraumatic stress disorder and report suicide attempts, whereas boys were more likely to meet the criterion for conduct disorder. In terms of utilization patterns, we would expect gender differences. The present study provides empirical assessment of the stability of patterns in first mental health service utilization across gender groups.

\section{Race/ethnicity}

Access to health care services varies by racial and ethnic group membership. Minorities are less likely to have health insurance, affecting their rates of utilization. Using data from the National Longitudinal Study of Adolescent Health, Kodjo and Auinger [20] found that black adolescents were less likely than white and Hispanic youth to receive psychological counseling. Racial/ethnic differences persisted after controlling for age, urban area, poverty, and health insurance status. Similarly, racial and ethnic minority adolescents exhibit higher overall rates of health care problems and lower rates of utilization [20].

In the general population, adolescent racial/ethnic minorities have limited access to health care, but what happens once these young people are living on the streets? Kipke et al. [15] studied street victimization and fear of violence in a sample of homeless youth in Los Angeles. They found that the influence of race/ethnicity on street victimization was nonsignificant. Rates of violent victimization for white, black and Hispanic youth did not differ. Kipke et al. [15] argue that homelessness surpasses racial/ethnic differences when youths are on the streets.

However, evidence of equality in the risk of violent victimization across racial/ethnic subgroups does not necessarily mean racial/ethnic equality in terms of service utilization or mental health care on the streets. Geber [11] found that racial/ethnic minority homeless adolescents reported barriers to health care service utilization based on racial/ethnic discrimination. Minority youth reported that fear of racism and racist behavior by health care workers was a major disincentive to seek services. Minority youth are likely to experience systematic barriers to health care service before leaving the home. Minority youth may be equally exposed to violent victimization on the streets, while simultaneously experiencing racial-ethnic discrimination by health care providers after leaving their homes.

\section{Family of origin stability}

The quality of family life for homeless and runaway youth is often examined in efforts to understand mental health outcomes $[4,5,8]$. In this study we focus on family transitions, parental rejection, and abuse. Family stability is related to runaway patterns for adolescents. Families who undergo re-composition changes (marriages, divorce, death) are at a higher risk for negative mental health outcomes. Similarly, geographic transitions introduce stressful life experiences into the lives of these homeless and runaway youth $[8,14]$. Transitions into foster care have also been linked to homelessness [21].

\section{Age on own}

Age on own is a proxy for increased risk of mental health problems. The timing of first runaway experience is found in many studies to covary with levels of vulnerability and risk behaviors. Whitbeck et al. [22] found that youth who run away at younger ages are more likely to engage in risk behaviors such as survival sex, stealing, selling drugs, and shoplifting. Youth who run away at younger ages are more likely to experience violence in their homes and to experience subsequent violence on the streets [23]. The timing of leaving home may influence patterns of first mental health service utilization. Younger runaways are at a higher risk for depression and negative mental health outcomes [14]. Youths who are on the street at younger ages should have an increased need for services, which may or may not translate into mental health service utilization.

\section{Social support/social networks}

Social support and social networks may be positively associated with health care utilization. Research suggests that social support plays a special role for these youth. Social networks provide access to advice on where to get services and how to recognize health problems as serious enough to go to the doctor [12] and [17]. Moreover, research suggests that social support itself acts as a buffer for physical and mental health problems [24]. Hatton's qualitative study with homeless women [25] found a pattern where social networks played an important role in how women used health care services. Women's social networks through contacts made in shelters with workers and other homeless people facilitated information exchange about where and how to get medical treatment. Ensign and Gittelsohn [2] and Ensign and Panke [16] found that youths used social networks consisting of friends, family members, and other adults for health information and advice regarding when and where to seek medical attention. Although qualitative work has emphasized the role of social networks and health, less work has been done in this area on larger nonclinical samples of homeless and runaway youth. 
Homeless shelters may provide youths with a chance to have mental health care needs addressed. When youth stay in shelters, their health needs may be treated [14]. Furthermore, shelter stays often initiate shelter workers into the youth's social networks, and these contacts provide information on where to seek health care. Klein et al. [26] studied health care needs and service utilization and found differences for shelter vs. nonshelter homeless youths. Indeed, shelter youths were more likely to use nonemergency services, whereas street youth were more likely to use hospitals.

\section{Family abuse and street victimization}

Family of origin abuse and street victimization are proxies for mental health needs. Links among abuse, victimization, and poor mental health outcomes are supported by previous research on homeless and runaway youth. Unfortunately, the present study does not provide information on specific mental health diagnoses at time of first running away or when youths first saw a mental health counselor. Thus, caretaker abuse and victimization are modeled as proxies for mental health needs, in addition to age of first runaway experience.

\section{Abuse before running away}

Prior research finds that parental rejection leads to negative emotional and behavioral outcomes for adolescents $[8,14,27]$. Parental abuse increases youths' vulnerability to future violence directly and indirectly through high risk behaviors [23]. In the current study, we argue that parental abuse affects when and if youth are initiated into a system of mental health care service. First, parental abuse may not lead to mental health care while the youths are at home. Abusive parents are not likely to ensure that their children receive care for a situation they are responsible for creating. Second, parental abuse may predict first mental health utilization in the postrun model. Many youth are running from abusive homes, thus, subsequent contacts with service providers offering mental health care may be actively sought out by the youths.

\section{Victimization after running away}

Adolescents living on the streets are vulnerable to physical and sexual victimization at higher rates compared with housed youth [15]. Victimization while on the street has been shown to influence depressive symptoms of homeless adolescents [22]. Exposure to street violence is one additional dimension of vulnerability to mental health disorders or emotional problems.

\section{Hypotheses}

Our analyses examine two phases during which adolescents could first see a mental health professional- before and after running away for the first time. From our literature review, we have several expectations about prerun intervention. First, youths from families with fewer financial resources will be less likely to receive care. Second, although caretaker abuse increases the need for mental health services, these youth will be less likely to receive care, assuming their mental health needs will be neglected. Third, racial discrimination will reduce the likelihood of non-Whites receiving care before running away. Girls will be more likely to see a mental health professional.

For postrun mental health intervention we expect younger first-time runaways to be more likely to see a mental health professional after running away. We also expect differences among youths who experience abuse in their families of origin. Many of these adolescents are running away from abusive family environments, and prior abuse may exacerbate youths' postrun mental health problems. Street victimization should increase the likelihood of mental health intervention, as victimization increases the need for these services. Moreover, social support will play a key role.

The processes involved in mental health service use may differ across race and gender groups. Thus, all findings must be verified for moderating effects. We tested interactions for race and each independent variable, gender and each independent variable, and racegender combinations, allowing us to examine nonwhite minority females as a subgroup. We expect females to have higher utilization rates compared with males. Adolescent females are more vulnerable to sexual victimization, which is a predictor of depression and posttraumatic stress disorder [23]. Furthermore, paternalistic practices of agencies may render females more deserving of protection and hence mental health care.

\section{Sample}

The Midwest Homeless and Runaway Adolescent Project was a study of 602 homeless and runaway youths [14]. To be eligible for this study, youth (aged 18 or younger) had to be currently homeless and unable or unwilling to return to their homes. Participants were located through the collaborative efforts of trained interviewers who worked out of offices located in homeless outreach agencies across the Midwest. Interviews were conducted by these outreach workers over an 18-month period. Homeless and runaway adolescents were interviewed in shelters, on the streets, and in drop-in centers in Nebraska, Kansas, Iowa, and Missouri.

Given their current circumstances, the majority of the youth were considered emancipated minors and were administered an informed consent protocol that was reviewed and approved by the National Institute of Mental Health and the university Institutional Review Board. For sheltered youth, parental consent was obtained when possible. Respondents were informed 
that caretaker abuse would be reported to social service agencies and that system referrals would be made if they appeared to be at immediate risk for harm. The combined response rate across all the interview locations was $93 \%$. Respondents were compensated for their time with a snack and a $\$ 15$ subject reimbursement.

\section{Measures}

\section{Dependent variables}

First mental health service utilization - Youths were asked to give the dates that they first ran away, as well as the date they first saw a mental health professional (if they did). We converted these variables to months and constructed a measure calculating the difference between leaving home for the first time and seeing a mental health professional for the first time. This variable was recoded into our two dependent variables. First Prerun utilization is coded as 1 if the adolescent saw a mental health professional for the first time before running away. First Postrun utilization is coded as 1 if the first time is after the youth left home. Adolescents who never saw a mental health professional are coded as 0 on both variables.

\section{Independent variables}

Measures of adolescent gender (coded 1 for female, 0 for male) and race/ethnic identification (coded 1 for white and 0 for nonwhite) were included as demographic control variables in each analysis.

Prerun measures included Family socioeconomic status (SES) background, which is measured by adolescents' reports of their primary caretaker's job status, education level, and welfare status (before the adolescent's first runaway episode). Caretaker Full-Time Work is a measure of whether the youth's primary caretaker ever worked full time (coded 1 for yes, 0 for no). Caretaker Education is measured on an ordinal scale ranging from 1 (grade school) to 9 (completed graduate degrees). Caretaker Welfare Status is a youth report on whether or not their pri- mary caretaker ever received welfare (coded 1 for yes, 0 for no). Family Transitions was computed as the average number of living transitions (e.g., change in adult supervision or moving to a new location) occurring per year before leaving home for the first time. Caretaker Rejection is a summed measured of adolescents' level of agreement with statements regarding caretakers not trusting or caring for them, being unhappy with them, and blaming them for things that were not their fault. The standardized Cronbach alpha for this scale is .79. Caretaker Abuse is measured by the average across 12 abuse items, including neglect and physical and sexual abuse (range from $0=$ never to $3=$ many times). The standardized Cronbach alpha for this scale is .82 .

Postrun measures included Age on own, the age that the adolescents were on their own for the first time. Social Support is measured by asking the youth how many people they could rely on for help and aid including loans, food, or shelter (ranged from $0=$ none to $10=10$ or more people). Shelter use is coded 1 if the adolescent ever spent time in a shelter and 0 for never used a shelter. Street Victimization is the average score across five victimization items, ranging from 0 (never) to 3 (many times). Items included being beaten up, robbed, asked or forced to engage in unwanted sexual behavior, and sexual assault. The standardized Cronbach alpha for this scale is .73.

\section{Analytic strategy}

This section presents descriptive findings first, including reasons for seeing a mental health professional the first time by racial/ethnic and gender group. Next, logistic regression is used to examine the likelihood of first mental health service use. The first set of models predicts prerun first mental health service utilization for the full sample. The second set analyzes postrun first utilization among youth who did not see a mental health practitioner before leaving home for the first time.

Table 1. Descriptive statistics $N=556$

\begin{tabular}{|c|c|c|c|c|c|}
\hline & Min & Max & Mean & SE (mean) & SD \\
\hline Prerun first utilization & 0 & 1 & .41 & .02 & .49 \\
\hline Female & 0 & 1 & .61 & .02 & .49 \\
\hline Caretaker work full-time & 0 & 1 & .59 & .02 & .49 \\
\hline Caretaker education & 1 & 9 & 5.44 & .06 & 1.36 \\
\hline Caretaker rejection & 5 & 25 & 14.03 & .19 & 4.44 \\
\hline Caretaker abuse & 0 & 2.75 & .94 & .02 & .58 \\
\hline Age on own & 4 & 20 & 13.51 & .11 & 2.56 \\
\hline Shelter use ever & 0 & 1 & .70 & .02 & .46 \\
\hline Social support & 0 & 10 & 3.02 & .10 & 2.34 \\
\hline Street victimization & 0 & 3 & .31 & .02 & .46 \\
\hline
\end{tabular}


Table 2. Proportions of pre- and postrun first time seeing a mental health professional by reason (multiple response)

\begin{tabular}{lccccc}
\hline & \multicolumn{2}{c}{ Prerun $\mathrm{n}=234$} & & \multicolumn{2}{c}{ Postrun $\mathrm{n}=228$} \\
\cline { 2 - 3 } \cline { 5 - 6 } & Mean & SD & & Mean & SD \\
\hline Depression & .38 & .49 & .46 & .50 \\
Suicide & .12 & .33 & .25 & .43 \\
Behavior problems & .52 & .50 & .54 & .50 \\
Family problems & .72 & .45 & .68 & .47 \\
Substance abuse & .09 & .29 & .15 & .36 \\
Other & .26 & .44 & .15 & .36 \\
\hline
\end{tabular}

\section{Results}

\section{Descriptive findings}

Table 1 reports descriptive statistics for the 556 cases with complete data used for analyses. Of the total sample, $80 \%$ report ever seeing a mental health professional. About $40 \%$ of youths report first seeing a mental health professional after running away. About $40 \%$ report first use before running away. Approximately $20 \%$ of the sample has never seen a mental health professional. On average, the age of these youths the first time they run away from home is 13.51 years. The sample is $61 \%$ female, $39 \%$ male. Sixty percent of the youths are white, $40 \%$ are nonwhite minorities.

Table 2 reports proportions of pre- and postrun first mental health intervention by reasons (multiple response). These baseline comparisons reveal differences in reasons for intervention and timing of first use. Adolescents whose first mental health contact followed the first time running away were more likely to report depression (post $=.46 \mathrm{vs}$. pre $=.38$ ), suicide (post $=.25$ vs. pre $=.12$ ) and substance use (post $=.15$ vs. pre $=.09$ ) as reasons. These findings suggest that the social context of homelessness and living on the street contribute to depression, suicide, and substance use. Similar proportions of pre and post youth reported behavior and family problems - suggesting that these factors are less affected by living on the streets.

Table 3 presents reasons for first utilization (multiple response) by the contextual variables race and gender. Similar gender patterns are found across racial groups for depression (females higher) and behavior problems (males higher). A three-way interaction among race, gender, and rates of family problems and substance abuse was significant. For nonwhite minorities, the average level of substance use for both males and females is .19. Overall, whites report substance abuse as a reason for first mental health use at a higher rate than minority youth. Among gender subgroups, an interesting pattern emerges. White males are most likely to report substance abuse (.21) and minority females are the least likely (.05). Minority males and females are significantly less likely than their white counterparts to report family problems as a reason. These findings illustrate how race and gender shape first mental health contacts and underscore the importance of including these contextual variables when analyzing first use.

\section{Multivariate models}

\section{First prerun utilization}

Table 4 reports logistic regression coefficients for models predicting first mental health service use before leaving home for the first time for the entire sample. Model 1 includes gender and race/ethnicity. White youths were significantly more likely see a mental health professional before they ran away $(\exp [\mathrm{b}]=1.47)$. Gender was not significant.

Model 2 adds family socioeconomic variables. We expected SES variables to be negatively associated with service use, and in model 2 these variables are not statistically significant. In this model, gender becomes significant, with adolescent females 1.39 times more likely than adolescent males to report prerun utilization. White adolescents are more likely to report service use compared with minority youth (white $\exp [\mathrm{b}]=1.44$ ).

In Model 3 we include the average number of family and geographic transitions. This variable is significantly positively associated with prerun utilization. Higher levels of transitions are associated with an increase in the odds of utilizing mental health services

Table 3. Means of reasons for seeing a mental health professional for the first time by race and gender (multiple response)

\begin{tabular}{|c|c|c|c|c|c|c|}
\hline & \multicolumn{3}{|c|}{ White } & \multicolumn{3}{|c|}{ Minority } \\
\hline & $\begin{array}{l}\text { Male } \\
(\mathrm{n}=97)\end{array}$ & $\begin{array}{l}\text { Female } \\
(\mathrm{n}=205)\end{array}$ & $\begin{array}{l}\text { Total } \\
(\mathrm{n}=302)\end{array}$ & $\begin{array}{l}\text { Male } \\
(\mathrm{n}=68)\end{array}$ & $\begin{array}{l}\text { Female } \\
(\mathrm{n}=99)\end{array}$ & $\begin{array}{l}\text { Total } \\
(\mathrm{n}=167)\end{array}$ \\
\hline Depression & $.36^{*}$ & $.49^{*}$ & .45 & $.25^{*}$ & $.45^{*}$ & .37 \\
\hline Suicide & .15 & .19 & .18 & .19 & .19 & .19 \\
\hline Behavior problems & $.64^{* *}$ & $.47^{* *}$ & .53 & $.66^{* *}$ & $.44^{* *}$ & .53 \\
\hline Family problems $\left.{ }^{* *}\right)$ & $.66^{* *}$ & $.81^{* *}$ & .76 & $.46^{* *}$ & $.70^{* *}$ & .60 \\
\hline Substance abuse $\left(^{*}\right)$ & .21 & .12 & .15 & .12 & .05 & .08 \\
\hline Other & .14 & .21 & .19 & .25 & .24 & .24 \\
\hline
\end{tabular}

* ANOVA test significant, $p<.01 ;{ }^{* *}$ ANOVA test significant, $p<.05 ;\left({ }^{*}\right)$ 3-way ANOVA test significant $p<.05 ;\left({ }^{* *}\right) 3$-way ANOVA test significant, $p<.01$ 
Table 4. Logistic regression coefficients predicting prerun mental health utilization (1st time) $\mathrm{N}=566$

\begin{tabular}{|c|c|c|c|c|c|c|c|c|}
\hline & \multicolumn{2}{|c|}{ Model 1} & \multicolumn{2}{|c|}{ Model 2} & \multicolumn{2}{|c|}{ Model 3} & \multicolumn{2}{|c|}{ Model 4} \\
\hline & $\mathrm{B}$ & $\operatorname{Exp}(B)$ & $\mathrm{B}$ & $\operatorname{Exp}(B)$ & B & $\operatorname{Exp}(B)$ & B & $\operatorname{Exp}(B)$ \\
\hline Female & .29 & 1.34 & $.33^{*}$ & 1.39 & $.32^{*}$ & 1.37 & .29 & 1.34 \\
\hline Caretaker work full-time & & & .18 & 1.20 & .23 & 1.26 & .24 & 1.27 \\
\hline Caretaker education & & & .10 & 1.10 & $.12^{*}$ & 1.13 & $.13^{*}$ & 1.14 \\
\hline Caretaker ever received welfare & & & .05 & 1.06 & -.02 & .99 & -.05 & .95 \\
\hline Caretaker abuse & & & & & & & -.11 & .90 \\
\hline Model chi-square & $8.07^{*}$ & & $12.01^{*}$ & & $23.72^{* *}$ & & $27.55^{* *}$ & \\
\hline df & 2 & & 5 & & 6 & & 8 & \\
\hline Improvement chi-square & & & 3.94 & & $11.70^{* *}$ & & 3.86 & \\
\hline $\mathrm{df}$ & 1 & & 3 & & 1 & & 2 & \\
\hline
\end{tabular}

${ }^{*} p<.05 ;{ }^{* *} p<.01$

$(\exp [b]=1.12)$. Caretaker work status and welfare status have no relationship to mental health utilization. However, caretaker education level is positively associated with prerun service use. Adolescents from families with higher levels of caretaker educational attainment are more likely to use prerun mental health services (exp[b] $=1.13$ ). Family transitions are positively associated with service use $(\exp [b]=3.06)$. The positive effects of being white and being female remain significant in this model (we tested for an interaction, but did not find one).

In Model 4, we include caretaker rejection and abuse. A small positive effect for rejection on likelihood of service use was found $(\exp [\mathrm{b}]=1.04)$. Abuse was not significantly associated with service use. Caretaker rejection has a small positive effect on the likelihood of prerun mental health utilization. We tested interactions between abuse and family transitions, and between rejection and family transitions - neither were significant, suggesting independent effects of these factors on ser- vice use. Not surprisingly, youths who are abused by their caretakers are not being initiated to mental health services while living at home. In fact, many of these adolescents are homeless in part as a way to escape abusive family environments. After controlling for caretaker abuse and rejection, the positive influence of being white and being female is reduced to nonsignificance, suggesting that caretaker rejection and abuse mediate the effects of race and gender [28].

\section{First postrun mental health service utilization}

The next set of models reported in Table 5 predict the likelihood of postrun first mental health intervention for respondents who did not see a practitioner before leaving home. In Model 1 we found stronger effects for female $(\exp [b]=2.08)$ and white $(\exp [b]=1.66)$ compared with our prerun models. Model 2 controls for street experience factors, all of which are significantly related to postrun utilization. Age on own is negatively related to

Table 5. Logistic regression models for postrun mental health utilization $(n=342) 1^{\text {st }}$ time

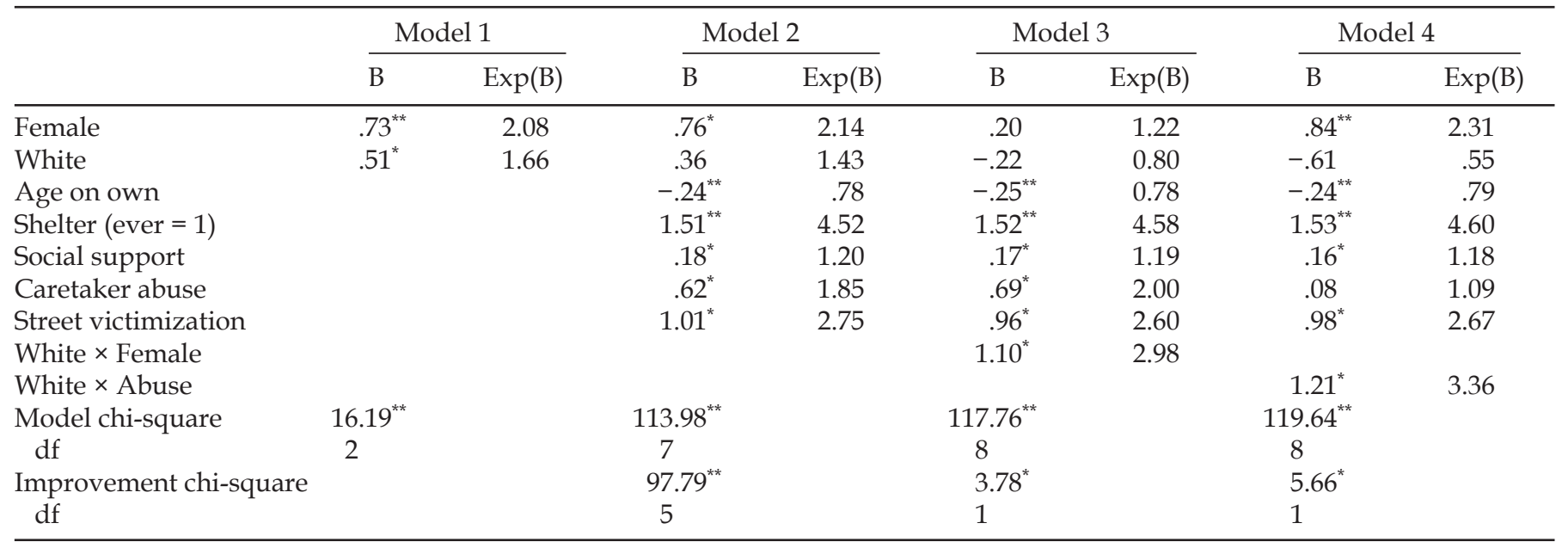

${ }^{*} p<.05 ;{ }^{* *} p<.01$ 


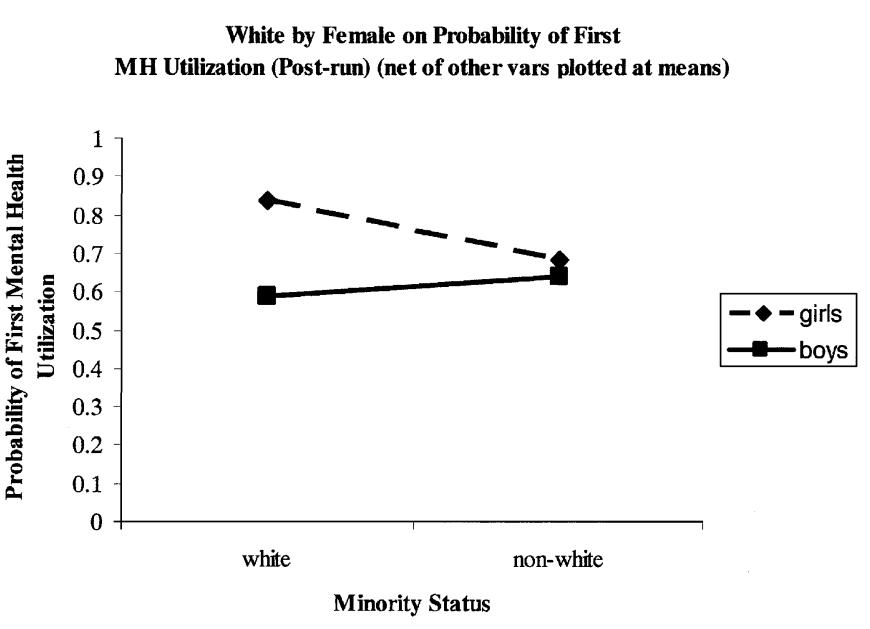

Figure 1. White by female on probability of first mental health utilization (post-run) (net of other variables plotted at means).

first postrun intervention in all of the models. Adolescents who transition to the street later are less likely to report first contact with mental health professionals after running away, compared with younger adolescents. Youth who stay at a shelter at any time point after running away are 4.6 times more likely to report a mental health intervention. This is not surprising, as shelters often offer counseling and psychological services to users. Social support increases the odds of first use, and this effect is not moderated by shelter use, suggesting multiple pathways to care for these youths. Abuse before leaving home increases the odds of first using mental health care after running away. Street victimization has a positive effect on the odds of using mental health care (exp[b] 2.75). Females still have a higher likelihood of using mental health services, whereas the race difference is reduced to nonsignificance.

Models 3 and 4 test for race and gender interaction effects. The effects of age on own, shelter use, social support, abuse, and street victimization are all positive and similar to model 2. The interaction between race and gender was significant, revealing postrun differences in first mental health utilization patterns. The gender gap in service use is substantial for whites, but not for minorities, suggesting alternate pathways to service use that cross gender and race boundaries (Figure 1). In Model 4, the interaction between race and abuse was significant. Whites who were abused were significantly more likely to receive mental health care after running away, compared with minorities who were abused (Figure 2).

\section{Discussion}

A significant portion of these youths received mental health care services before they ran away from home the first time. Family abuse did not predict prerun intervention; however, parental rejection had a slight positive effect on the likelihood of seeing a mental health profes-
White by Abuse on Post-Run First Mental Health Service Utilization (net of controls plotted at their means)

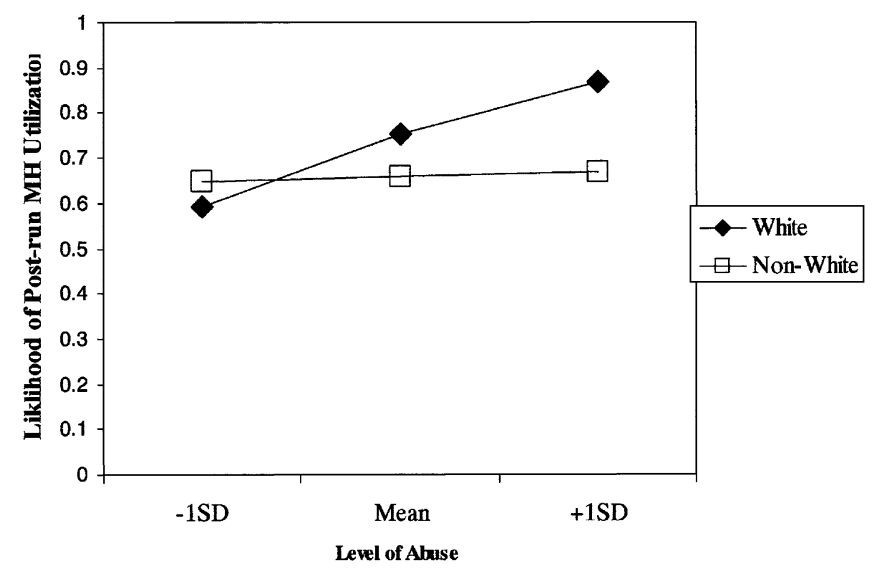

Figure 2. White by abuse on postrun first mental health service utilization (net of controls plotted at their means).

sional for the first time. The latter finding may be sample driven, and future research should tease out the effects of caretaker abuse and rejection and their relationship to service use. Levels of family instability are strongly associated with prerun intervention. This finding should be explored further. In our data, distinctions between types of transitions are not important (analyses not shown). Family stability and socioeconomic resources are more important than race, gender, or caretaker abuse.

Notably, caretaker abuse does not predict prerun intervention but it increases the likelihood of postrun intervention. In the postrun intervention models, adolescents who run away early, use shelters, and maintain social support networks are more likely to be initiated to mental health care services. Postrun first service use seems to be driven by street contacts and experiences, whereas prerun use is associated with family socioeconomic status and instability. Our findings support the notion that social support networks are related to first service utilization in the postrun models. Future research should determine exactly how social supports increase utilization; are they a source of information on health care problems and solutions, or do these supportive individuals urge the youths to seek help? We cannot know from these data.

\section{Clinical significance}

This study includes findings that are likely to be of clinical relevance to service providers. The cumulative effects of family of origin abuse on postrun mental health needs and utilization should be addressed. Youths who are abused are more vulnerable and also more likely to visit a mental health professional for the first time after running away. Mental health concerns change after running away from home. Depression, suicide attempts, and substance use were reported more among the postrun first visit youths. 
The pre-post first use distinction allows us to assess the circumstances leading to service use. Different factors predict early interventions before running away. Once these youth are on the streets, social networks, shelter use, victimization and race-ethnicity become important predictors of mental health intervention. Importantly, homelessness does not equalize race and gender differences in first mental health contact. Structural barriers exist for post-run racial ethnic minority youth. Abused racial-ethnic minority adolescents are falling through the cracks. Special programs should focus on providing services to this underserved group of homeless youth.

\section{Limitations}

The current study has some limitations. The data lack specific measures of unmet mental health needs and problems. Age on own, caretaker abuse, and street victimization are modeled as proxies for need, as evidence suggests they are strong predictors of mental health disorders $[7,27]$. The current study findings are, thus, suggestive and future studies should examine specific mental health needs and how they relate to specific service utilization outcomes.

Second, these data do not include measures of frequency, duration, or quality of mental health care access. We are limited to looking at whether or not youths ever use mental health care and the timing of first visits. We cannot distinguish between voluntary and involuntary service utilization. Adolescents who seek out help voluntarily may be different from adolescents who are required to see a mental health counselor to stay in a shelter or as part of contact with other institutions such as law enforcement. Disentangling the institutional context of first service use is impossible to do with these data.

Although $20 \%$ of our sample never received mental health care, researchers need more information on the $80 \%$ who did. We present evidence of differential pathways to treatment, and the prerun/postrun distinction is an important dimension. More information is needed regarding the duration, quality, and outcomes of service use, as well as barriers to receiving mental health care. Researchers need to know more about the conditions under which mental health services are accessible for these youth.

Finally, these data are from a study where the initial data collection occurred approximately 8 years ago. This could be a concern regarding the timeliness of these findings if there had been major shifts in the study population or the services available. However, given the general lack of funding for outreach services to this population, and no substantial improvement in this situation over the past few years, it is likely that the findings from this study are just as appropriate today as when these data were first gathered.

Even with these limitations, our models suggest many important dynamics that are likely to affect ser- vice utilization patterns among homeless and runaway adolescents. We found evidence that the process of service utilization may differ within race and between genders as well as across racial/ethnic groups. Future research should address race and gender-based gaps in first mental health service utilization among this population of adolescents.

\section{Conclusion}

Our findings support the need for research providing a contextual understanding of service use for this population of adolescents. Most studies assume that homeless youth only have access to hospital services for health care arising from acute problems. This study illustrates the complexity of care; homeless youth are utilizing health care resources not necessarily tied to hospital visits.

We documented variation in first mental health service contact among homeless and runaway youth. We discovered that youths are initiated into care at different points in their lives; pre- or postrun. At these different times, the reasons for first seeing a mental health professional vary (Table 2). Importantly, parental abuse and street victimization play a factor in service use, increasing the need as well as the incidence of first utilization for postrun white females in particular. Is mental health service use a function of self-help-seeking behavior, or is it a step or requirement for youths to gain access to other services they need? Is mental health service use a function of paternalistic (through race and gender) labeling processes by authorities in social services and the juvenile justice system? Are there stigmas attached to receiving or seeking care for mental health difficulties that prevent subgroups of adolescents from receiving needed services? For homeless and runaway youth especially, these factors likely play a role in mental health intervention, perhaps independent of mental health needs. As argued by Ensign [12], researchers need to talk to these young people about how, why, where, and under what conditions they seek out and use mental health services.

Finally, prerun family factors and street experiences exacerbate mental health vulnerabilities and are associated with an increased likelihood of postrun first service utilization. Street victimization, shelter use, and social support after running away from home are positively related to mental health intervention. These findings are consistent with previous studies finding links between family of origin abuse and subsequent street victimization effects on depression, substance abuse, and conduct disorder [14, 22]. Family-of-origin experiences, particularly caretaker abuse, increase these youths' vulnerability to a variety of mental health problems. Adolescents who are abused before running away may be more vulnerable to developing mental health disorders after running away, heightening their need for services. 


\section{References}

[1] Morey MA, Friedman LS. Health care needs of homeless adolescents. Curr Opin Pediatr 1993; 5:395-9.

[2] Ensign J, Gittelsohn J. Health and access to care: perspectives of homeless youth in Baltimore city, U. S. A. Soc Sci Med 1998; 47: 2087-99.

[3] Yates GL, Pennbridge J, Swofford A, et al. The Los Angeles system of care for runaway/homeless youth. J Adolesc Health 1991; 12:555-60.

[4] Cauce AM. The characteristics and mental health of homeless adolescents: age and gender differences. J Emotional Behav Dis 2000; 8:230-40.

[5] Feitel B, Margetson N, Chamas J, et al. Psychosocial background and behavioral and emotional disorders of homeless and runaway youth. Hosp Community Psychiatry 1992; 43:155-9.

[6] Greenblatt M, Robertson MJ. Life-styles, adaptive strategies, and sexual behaviors of homeless adolescents. Hosp Community Psychiatry 1993; 44:1177- 80.

[7] Padgett DK, Struening EL. Victimization and traumatic injuries among the homeless. Am J Orthopsychiatry 1992; 62:525-34.

[8] McCaskill PA, Toro PA, Wolfe SM. Homeless and matched housed adolescents: a comparative study of psychopathology. J Clin Child Psychol 1998; 27:306 -19.

[9] Health care needs of homeless and runaway youth. Council on Scientific Affairs. JAMA 1989; 262:1358-61.

[10] Kipke MD, Unger JB, O'Connor S, et al. Street youth, their peer group affiliation and differences according to residential status, subsistence patterns, and use of services. Adolescence 1997; 32:655- 69.

[11] Geber GM. Barriers to health care for street youth. J Adolesc Health 1997; 21:287-90.

[12] Ensign J. Health issues of homeless youth. J Soc Distress Homeless 1998; 7:159 -75.

[13] Kushel MB, Perry S, Clark R, et al. Emergency department use among the homeless and marginally housed: results from a community- based study. Am J Public Health 2002; 92:778-85.

[14] Whitbeck LB, Hoyt DR. Nowhere to Grow: Homeless and Runaway Adolescents and their Families. New York, NY: Aldine de Gruyter, 1999.
[15] Kipke MD, Simon TR, Montgomery SB, et al. Homeless youth and their exposure to and involvement in violence while living on the streets. J Adolesc Health 1997; 20:360 -7.

[16] Ensign J, Panke A. Barriers and bridges to care: voices of homeless female adolescent youth in Seattle, Washington, USA. J Adv Nurs 2002; 37:166 -72.

[17] Ensign J. Illness experiences of homeless youth: age and gender differences. J Adolesc Health 2003; 32:137-9.

[18] Barkin SL, Balkrishnan R, Manuel J, et al. Health care utilization among homeless adolescents and young adults. $J$ Adolesc Health 2003; 32:253- 6.

[19] Piliavin I, Westerfelt A, Wong YI, et al. Health status and health care utilization among the homeless. Soc Serv Rev 1994; 237-53.

[20] Kodjo C, Auinger P. Racial/ethnic differences in emotionally distressed adolescents receiving mental health care. $J$ Adolesc Health 2003; 32:132-3.

[21] Roman NP, Wolfe PB. The relationship between foster care and homelessness. Public Welf 1997; 55:4 -9.

[22] Whitbeck LB, Hoyt DR, Yoder KA, et al. Deviant behavior and victimization among homeless and runaway adolescents. J Interpers Violence 2001; 11:1175-1204.

[23] Tyler KA, Hoyt DR, Whitbeck LB, et al. The impact of childhood sexual abuse on later sexual victimization among runaway youth. J Res Adolesc 2001; 11:151-77.

[24] Unger JB, Kipke MD, Simon TR, et al. Stress, coping, and social support among homeless youth. J Adolesc Res 1998; 13:134-57.

[25] Hatton DC. Homeless women's access to health services: a study of social networks and managed care in the US. Women Health 2001; 33:149-62.

[26] Klein JD, Woods AH, Wilson KM, et al. Homeless and runaway youths' access to health care. I Adolesc Health 2000; 27:331-9.

[27] Whitbeck LB, Hoyt DR, Ackley KA. Abusive family backgrounds and later victimization among runaway and homeless adolescents. J Res Adolesc 1997; 7:375-92.

[28] Baron RM, Kenny DA. The moderator-mediator variable distinction in social psychological research: conceptual, strategic, and statistical considerations. J Pers Soc Psychol 1986; 51:1173- 82. 